\title{
Article \\ Infrared Spectroscopic Analysis of the Inorganic Components from Teeth Exposed to Psychotherapeutic Drugs
}

\author{
Camila Diez ${ }^{1,2}$, Maria Ángeles Rojo ${ }^{3, *(\mathbb{C}}$, Jesús Martín-Gil ${ }^{4}\left(\mathbb{D}\right.$, Pablo Martín-Ramos ${ }^{5}\left(\mathbb{C}\right.$, Manuel Garrosa ${ }^{2}(\mathbb{C})$ \\ and Damián Córdoba-Diaz ${ }^{6}$ (D) \\ 1 Area of Health Sciences, Miguel de Cervantes European University, C. del Padre Julio Chevalier 2, \\ 47012 Valladolid, Spain; cdiez@uemc.es \\ 2 Area of Histology, Faculty of Medicine and INCYL, University of Valladolid, 47005 Valladolid, Spain; \\ manuel.garrosa@uva.es \\ 3 Area of Experimental Sciences, Miguel de Cervantes European University, C. del Padre Julio Chevalier 2, \\ 47012 Valladolid, Spain \\ 4 Agriculture and Forestry Engineering Department, ETSIIAA, University of Valladolid, Avenida de Madrid 44 \\ 34004 Palencia, Spain; mgil@iaf.uva.es \\ 5 Instituto Universitario de Investigación en Ciencias Ambientales de Aragón (IUCA), EPS, \\ Universidad de Zaragoza, Carretera de Cuarte s/n, 22071 Huesca, Spain; pmr@unizar.es \\ 6 Institute of Industrial Pharmacy (IUFI), Complutense University of Madrid, 28040 Madrid, Spain; \\ damianco@farm.ucm.es \\ * Correspondence: marojo@uemc.es
}

check for updates

Citation: Diez, C.; Rojo, M.Á.; Martín-Gil, J.; Martín-Ramos, P.; Garrosa, M.; Córdoba-Diaz, D. Infrared Spectroscopic Analysis of the Inorganic Components from Teeth Exposed to Psychotherapeutic Drugs. Minerals 2022, 12, 28. https:// doi.org/10.3390/min12010028

Academic Editor:

Pedro Álvarez-Lloret

Received: 12 October 2021

Accepted: 20 December 2021

Published: 24 December 2021

Publisher's Note: MDPI stays neutral with regard to jurisdictional claims in published maps and institutional affiliations.

Copyright: (C) 2021 by the authors. Licensee MDPI, Basel, Switzerland. This article is an open access article distributed under the terms and conditions of the Creative Commons Attribution (CC BY) license (https:// creativecommons.org/licenses/by/ $4.0 /)$.

\begin{abstract}
Teeth are unique and complex anatomical organs that can provide relevant data about a person's health, and play an important role in forensic medicine. Teeth are exposed to food, drinks, and the microbiota of the oral cavity; therefore, they have developed a high resistance to localized demineralization. Nevertheless, the continuous demineralization-remineralization cycle present in the oral environment can be influenced by stress, medication, mineralization agents, and other factors such as individual habits, especially diet. In this study, based on attenuated total reflectance Fourier-transform infrared spectroscopy (ATR-FTIR) spectra from tooth samples of 36 patients, several parameters were estimated: the crystallinity index $(\mathrm{CI})$, the phosphate/amide I ratio, and the carbonate/phosphate ratio. In addition, in eight representative samples (six of the root of the tooth and two of the enamel area of the crown), additional characterization by $\mathrm{X}$-ray powder diffraction (XRPD), scanning electron microscopy (SEM) and energy-dispersive X-ray spectroscopy (EDS) was conducted. From the FTIR data, it was observed that the highest CI values were found in patients who smoked. Further, in both root and crown samples, the intensity of the absorption band corresponding to $\mathrm{PO}_{4}{ }^{3-}$ increased in patients undergoing treatment with psychotherapeutic drugs. On the other hand, the intensity of the absorption band of the amide I group decreased with medical treatment and with the patient's biological age. Moreover, it was found that the remineralization process was more active in enamel than in the root due to direct contact with saliva. Regarding the results obtained from the X-ray powder diffractograms, exposure to psychotherapeutic drugs affected the definition of the peaks corresponding to hydroxyapatite, both in the crown and root samples. Concerning SEM results, qualitative differences in the stratification process in demineralized surfaces were observed, and EDS analyses showed some differences in the $\mathrm{Ca} / \mathrm{P}$ ratio between pathological samples and control ones, but without clear patterns. The above techniques, in particular ATR-FTIR, showed promise for the investigation of the effect of changes produced in the hydroxyapatite structure in teeth and, consequently, to determine possible strategies in the diagnostic protocol.
\end{abstract}

Keywords: ATR-FTIR; EDS; remineralization; tooth; psychotherapeutic drugs; SEM; XRPD

\section{Introduction}

Among the different methods for evaluating the biological age of people and thus determining their psychological maturity, and for verifying the effects of systematic pathologies, the study of the development of teeth is perhaps one of the safest and most reliable 
approaches [1]. From an academic-forensic point of view, each tooth has unique characteristics that are part of the basis of the person's identification [2,3]. It must be taken into consideration that teeth age is conditioned by eating habits and by the pathologies or anomalies that they may present. Therefore, all dental characteristics must be considered [4].

The tooth is the most mineralized tissue in the human body. In its anatomical structure, we can differentiate crown and root, and their histological components dentin and cementum are individually or jointly used to determine the age of an individual [5], based both on their organic and inorganic compounds. Biological apatite is the main inorganic component [6], while noncollagenic proteins, among which amelogenin stands out, account for most of the organic part $[7,8]$.

Due to the action of saliva, teeth are subject to different demineralization and remineralization cycles [9]. In these processes, teeth can lose minerals when they are in contact with an acid, and those minerals can be reincorporated when the $\mathrm{pH}$ of the environment surrounding the tooth in the oral cavity is restored $[10,11]$.

Among the components of the tooth, the present paper focuses on the analysis of enamel and cement. The enamel protects the dentin at the crown level in a similar way as the cementum that surrounds the dentin does at the level of the anatomical root of the tooth. Among the existing methods for their analysis, one may find clinical, radiographic, histological, and physicochemical diagnostic approaches $[12,13]$.

Enamel is made up of an inorganic matrix $(96 \%, w / w)$; some organic components such as proteins (90\% amelogenin) [14]; and a small proportion of collagen, lipids, and water $(4 \%, w / w)$. In turn, calcium, phosphates, carbonates, magnesium, and sodium are among the main mineral constituents of tooth enamel $[7,15]$. Concerning the cement of the root zone, it contains organic components (among which type I collagen is the main constituent) and mineral components (approximately 45\%), among which calcium phosphate stands out [16], as it gives the tooth its characteristic hardness.

Crown enamel is the material that supports most of the changes during the tooth development process. During the early stages of the tooth, the proportion of the protein component is greater than that of the inorganic component. However, in successive stages, organic components are replaced by inorganic ones [7]. Regarding the inorganic components of enamel, hydroxyapatite $\left(\mathrm{Ca}_{10}\left(\mathrm{PO}_{4}\right)_{6}(\mathrm{OH})_{2}\right)$ is the most abundant [17], and its incorporation into the tooth progressively increases as age advances $[18,19]$. Bioapatite is also part of the composition and corresponds to hydroxyapatite carbonate, in which the $\mathrm{Ca} / \mathrm{P}$ ratio has a lower value than that of hydroxyapatite [20]. These minerals belong to the group of bioactive and biocompatible materials available in teeth. Due to the replacement or substitution processes of calcium and phosphate ions in biological apatite, their proportion is different from that of the stoichiometry of hydroxyapatite [21]. Furthermore, one can find other elements distributed in different proportions in the solid nanocrystals of the apatite structure. Additionally, it has been reported that carbonated apatite is relatively easy to dissolve in the presence of acids [7,22].

During the demineralization process, calcium ions and phosphates from the enamel in the crown zone are the first to be released. This is the reason why its contribution is essential in the remineralization of teeth, as Cummins et al. [23] observed during the development of dental caries. It must also be borne in mind that the demineralization/remineralization phenomena are a continuous cycle, but at the same time a variable one that is repeated with food intake and with the salivary supply of proteins and enzymes. The enamel surface is especially rich in calcium and phosphate ions, whose contents, which exceed those of the hydroxyapatite structure, facilitate remineralization [9]. Thus, the remineralization capacity of the demineralized enamel surface is determined by the availability of fluoride, calcium, and phosphate ions, as well as the nature of the salivary content [24], in such a way that only when the collapse of the structural matrix of the protein takes place is the process irreversible [9]. 
A recent publication [25] reported an increase in eroded teeth with alcohol consumption from an epidemiological point of view and, although limited in its objectives and methodology, aroused enough interest to motivate the present study, which aimed to assess the effects of psychotherapeutic drugs on all these processes, an issue that has not received much attention to date.

The purpose of this work was to illustrate, through the mineral composition and the particular characteristics of teeth from patients with different clinical histories; the presence of processes of dental nucleation and growth of biomineralized structures; and the influence of factors such as age, tobacco and alcohol consumption habits, and the intake of anti-inflammatory and psychotherapeutic drugs (considering as such those chemical substances that have a specific pharmacological effect on mental disorders). Such analysis is of interest in professional practice because the composition of the tooth is directly related to the hardness of the patient's teeth, their possible response to future dental treatments, and the care that the patient must be provided to improve their health [26,27].

As the main methodology applied to the study of the inorganic components of the tooth, Fourier-transform infrared spectroscopy (FTIR), a vibrational spectroscopy technique able to provide unique spectra for molecules that has been used in the analysis of biological tissues for diagnosis purposes [28,29], was selected. FTIR is based on the molecular vibrations experienced by different groupings of atoms of a mineral nature (e.g., $\mathrm{PO}_{4}{ }^{3-}$ ) and the functional groups of components of organic nature (e.g., collagen amides) that make up the tooth. The information this technique provides is based on the fact that the intensity absorption of infrared radiation is proportional to the degree of change in the dipole moment of the covalent bond during vibration. FTIR has been used to establish structural differences and study the degree of substitution of bioinorganic materials [30-33]. Such materials have a great variability with respect to their chemical composition, which fundamentally depends on the biological process that has led to their formation and, in the case of teeth affected by various pathologies, on the patient's habits. The area or height of the bands is considered as a measure for the quantitative analysis of the main components present in dental samples [34].

Secondarily, in a complementary way, the information provided by X-ray powder diffraction (XRPD) patterns was collected for selected samples. XRPD is a nondestructive method that reveals internal lattice data of crystalline substances. For example, XRPD patterns can provide information on the composition and crystallinity of teeth, and certain reflections - such as (002) and (310) — can be used to evaluate the longitudinal and transverse size of crystalline hydroxyapatite microcrystals. The investigation was completed with scanning electron microscopy (SEM) and energy-dispersive X-ray spectroscopy (EDS) to examine the surface characteristics and elemental composition.

\section{Materials and Methods}

\subsection{Sample Preparation}

In the present study, 36 permanent molar and incisor teeth from patients aged between 21 and 78 years old were considered. Once the patients' medical records were obtained and their oral health was evaluated, teeth were extracted from consenting patients at the Oral Surgery Clinic of European Miguel de Cervantes University and at Dr. Diez-Arauz's clinics. The collected teeth did not present apparent fractures in dental radiographs. Immediately after extraction, the samples were thoroughly rinsed with distilled water, air-dried, and stored at room temperature in plastic boxes.

The variables collected for the study were age, sex, and drug intake prescribed by a physician (Table 1). Subsequently, teeth were classified considering the habits of the patient (smoker/alcohol consumption) and their medical treatment (antiepileptic, schizophrenia treatment, anti-inflammatory, and chemotherapy drugs). Within the term "psychotherapeutic drugs", treatments with valproic acid, risperidone, lorazepam, and tramazoline hydrochloride were considered, and within the term "anti-inflammatory", patients who ingested paracetamol or ibuprofen were grouped. 
Table 1. Crystallinity index, and degrees of mineralization and carbonation.

\begin{tabular}{|c|c|c|c|c|c|c|c|c|}
\hline \multirow{2}{*}{ Group } & \multirow{2}{*}{$\begin{array}{l}\text { Age } \\
\text { (Years) }\end{array}$} & \multirow[b]{2}{*}{ Sex } & \multicolumn{3}{|c|}{ Crown Enamel } & \multicolumn{3}{|c|}{ Root Cementum } \\
\hline & & & $\begin{array}{l}\text { Crystallinity } \\
\text { Index }\end{array}$ & $\begin{array}{l}\text { Mineralization } \\
\text { Degree }\end{array}$ & $\begin{array}{l}\text { Carbonation } \\
\text { Degree }\end{array}$ & $\begin{array}{l}\text { Crystallinity } \\
\text { Index }\end{array}$ & $\begin{array}{l}\text { Mineralization } \\
\text { Degree }\end{array}$ & $\begin{array}{c}\text { Carbonation } \\
\text { Degree }\end{array}$ \\
\hline \multirow{12}{*}{$\mathrm{C}$} & 18 & $\mathrm{~F}$ & 2.02 & 20.97 & 0.16 & 2.21 & 4.08 & 0.17 \\
\hline & 20 & M & 2.39 & 18.62 & 0.02 & 2.06 & 2.72 & 0.26 \\
\hline & 32 & $\mathrm{~F}$ & 2.48 & 2.04 & 0.24 & 1.90 & 2.47 & 0.33 \\
\hline & 33 & $\mathrm{~F}$ & 2.26 & 3.03 & 0.27 & 2.22 & 2.26 & 0.04 \\
\hline & 33 & $\mathrm{~F}$ & 2.34 & 7.45 & 0.21 & 1.97 & 2.89 & 0.26 \\
\hline & 39 & M & 2.10 & 1.77 & 0.28 & 1.79 & 1.79 & 0.05 \\
\hline & 47 & M & 2.90 & 21.34 & 0.13 & 2.15 & 4.07 & 0.23 \\
\hline & 48 & $\mathrm{~F}$ & 2.56 & 23.87 & 0.13 & 2.05 & 3.23 & 0.25 \\
\hline & 53 & $\mathrm{~F}$ & 1.70 & 9.37 & 0.22 & 2.10 & 2.66 & 0.29 \\
\hline & 56 & M & 2.02 & 2.72 & 0.27 & 1.76 & 1.81 & 0.32 \\
\hline & 65 & M & 2.00 & 3.48 & 0.35 & 1.92 & 2.11 & 0.05 \\
\hline & 68 & M & 2.44 & 18.36 & 0.15 & 1.96 & 2.47 & 0.17 \\
\hline \multirow{15}{*}{$S$} & 21 & $\mathrm{~F}$ & 2.63 & 2.47 & 0.24 & 2.52 & 5.44 & 0.02 \\
\hline & 23 & M & 2.71 & 6.44 & 0.23 & 2.35 & 5.88 & 0.04 \\
\hline & 24 & $\mathrm{~F}$ & 1.00 & 9.24 & 0.16 & 1.76 & 1.86 & 0.32 \\
\hline & 26 & M & 2.68 & 2.79 & 0.26 & 1.85 & 2.44 & 0.37 \\
\hline & 29 & $\mathrm{~F}$ & 1.98 & 7.98 & 0.14 & 2.18 & 2.11 & 0.34 \\
\hline & 32 & M & 2.57 & 13.44 & 0.18 & 1.65 & 2.69 & 0.02 \\
\hline & 40 & $\mathrm{~F}$ & 2.58 & 6.80 & 0.01 & 2.02 & 1.65 & 0.08 \\
\hline & 43 & $\mathrm{~F}$ & 1.58 & 4.48 & 0.27 & 2.21 & 2.35 & 0.03 \\
\hline & 55 & $\mathrm{~F}$ & 2.06 & 3.28 & 0.20 & 2.94 & 3.14 & 0.23 \\
\hline & 55 & $\mathrm{~F}$ & 2.26 & 6.25 & 0.01 & 1.87 & 2.46 & 0.24 \\
\hline & 56 & $\mathrm{~F}$ & 2.40 & 17.29 & 0.16 & 2.30 & 3.92 & 0.18 \\
\hline & 59 & $\mathrm{~F}$ & 4.97 & 21.37 & 0.11 & 2.02 & 3.05 & 0.20 \\
\hline & 59 & M & 2.18 & 3.86 & 0.19 & 1.94 & 1.94 & 0.04 \\
\hline & 66 & $\mathrm{~F}$ & 2.54 & 17.22 & 0.15 & 0.23 & 4.62 & 0.17 \\
\hline & 78 & M & 2.61 & 9.95 & 0.16 & 2.40 & 28.44 & 3.94 \\
\hline M & 61 & $\mathrm{~F}$ & 2.34 & 6.42 & 0.18 & 1.92 & 1.64 & 0.15 \\
\hline S-A & 62 & $M$ & 2.11 & 3.44 & 0.54 & 1.96 & 3.71 & 0.08 \\
\hline $\mathrm{S}-\mathrm{CT}$ & 32 & $\mathrm{M}$ & 2.63 & 27.06 & 0.13 & 2.16 & 4.17 & 0.25 \\
\hline S-AA & 60 & M & 1.95 & 2.05 & 0.31 & 1.82 & 2.07 & 0.08 \\
\hline \multirow{4}{*}{ S-M } & 25 & $M$ & 2.08 & 14.16 & 0.01 & 2.14 & 1.25 & 0.07 \\
\hline & 40 & M & 1.74 & 2.75 & 0.03 & 2.06 & 1.75 & 0.13 \\
\hline & 47 & $\mathrm{~F}$ & 2.10 & 26.08 & 0.11 & 2.15 & 2.66 & 0.20 \\
\hline & 43 & M & 2.04 & 1.92 & 0.29 & 2.52 & 2.15 & 0.40 \\
\hline
\end{tabular}

$\mathrm{C}=$ control; $\mathrm{S}=$ smoker; $\mathrm{M}=$ treatment with psychotherapeutic drugs; $\mathrm{A}=$ alcohol; $\mathrm{CT}=$ chemotherapy; $\mathrm{AA}=$ anti-inflammatory drugs.

Finally, those individuals showing a healthy status of their oral evaluation, devoid of any medical prescription and with healthy habits, were included in the control group.

\subsection{ATR-FTIR Spectroscopy}

Vibrational spectra of the samples from root cementum and enamel of all pieces were measured in the $400-4000 \mathrm{~cm}^{-1}$ spectral range, using a Thermo Scientific (Waltham, MA, USA) Nicolet iS50 FTIR spectrometer equipped with an inbuilt diamond attenuated total reflection (ATR) system. Spectra were recorded at room temperature with $1 \mathrm{~cm}^{-1}$ spectral resolution, with a total of 64 scans collected. The powder of enamel or root cementum was extracted with a dental turbine to obtain a fine powder. The crown area studied was taken from one side of the tooth identified by the dentin apex, both in the molars and in the incisors. 
After comparing the vibrational spectra of the samples, eight representative samples that showed differences in their vibrational spectra (six samples from root cementum and two from enamel) were selected, considering the patients' medical history. In this case, FTIR spectra were collected in transmission mode using the $\mathrm{KBr}$ pellet method. $\mathrm{KBr}$ pellets were prepared by mixing $2 \mathrm{mg}$ of root and crown powder with $200 \mathrm{mg}$ of $\mathrm{KBr}$ in an agate mortar and pressing the pellets in a $0.1 \mathrm{~mm}$ pellet die [35].

The crystallinity index was calculated from vibrational data as the ratio between the intensities of the bands at $1030 \mathrm{~cm}^{-1}$ and $960 \mathrm{~cm}^{-1}$ [36]. The degree of mineralization was determined considering the amount of mineral phosphate (960-1030 $\left.\mathrm{cm}^{-1}\right)$ and amide type I related area $\left(1650-1780 \mathrm{~cm}^{-1}\right)$ [37]. The carbonation degree was estimated from the ratio of the amount of carbonate $\left(860-890 \mathrm{~cm}^{-1}\right)$ with respect to the amount of mineral phosphate (960-1030 $\left.\mathrm{cm}^{-1}\right)$. The conditions of patients' teeth were indicated as follows: alcohol (A), smoker (S), treatment with psychotherapeutic drugs (M), anti-inflammatory drugs (AA), chemotherapy (CT), and control (C). The age of each patient is shown in parentheses.

\subsection{X-ray Diffraction Analysis}

X-ray powder diffraction patterns were recorded on a Bruker (Billerica, MA, USA) D8 Advance $X$-ray diffractometer with a $\mathrm{Cu} \mathrm{K} \alpha$ anode $(\lambda=0.1542 \mathrm{~nm})$ operating at $40 \mathrm{kV}$ and $30 \mathrm{~mA}$. The diffraction patterns were collected at $25{ }^{\circ} \mathrm{C}$ and over an angular range of $5^{\circ}$ to $70^{\circ}$. The obtained pattern was matched to stoichiometric hydroxyapatite (HAP) (JCPDS, card number 00-901-3627) from the Powder Diffraction File-2 (PDF-2) database of the International Centre for Diffraction Data (ICDD).

The degree of crystallinity was analyzed using the peak intensities in the $2 \theta=20^{\circ}-70^{\circ}$ range, according to the procedure described by Behroozibakhsh et al. [38].

\subsection{Scanning Electron Microscopy and Energy-Dispersive X-ray Spectroscopy}

Scanning electron microscopy observations were carried out with a field-emission ESEM (model QUANTA 200 FEG; FEI Co., Hillsboro, OR, USA). The selected samples were analyzed in low-vacuum conditions, using a secondary electron (LFD) detector. Micrographs of the enamel and root were obtained at $400 \times, 2000 \times$, and $4000 \times$ magnification. EDS data was collected with an EDAX Genesis module coupled to the ESEM.

\subsection{Statistical Analysis}

Because of the small sample size, Friedman's nonparametric test was used for finding differences between treatments.

\section{Results}

\subsection{ATR-FTIR Analysis}

The information from the crown enamel and root cementum samples of the 36 teeth analyzed by ATR-FTIR is shown in Table 1.

The degree of crystallinity of the crown enamel increased with the patient's age, both in the control group and in patients under psychotherapeutic treatment (Table 1). When the tobacco variable was considered, the crystallinity was found to be related to the amount of nicotine inhaled, so that in the groups in which tobacco was considered, the values were high even at young ages. Another was the case for the dental root cementum area, in which the crystallinity decreased with the age of the patient. The difference with the enamel of the crown is related to the function it performs in the oral cavity.

The relationship between the area of the $v_{1}, v_{3}$ phosphate vibration $\left(959-1030 \mathrm{~cm}^{-1}\right.$ ) and that of the amide I vibration (1650-1780 $\mathrm{cm}^{-1}$ ) was directly related to the mineral content. The degree of mineralization of the samples, as shown in Table 1, was higher in crown enamel samples than in root cementum samples. No specific pattern attributable to external factors differentiating these groups was observed.

In order to compare the mechanical properties of the collected teeth, considering the external agents to which they had been exposed, their calculated mineralization degree 
values versus their crystallinity values were represented in a dispersion diagram (Figure 1). Three groups were considered: control group, including teeth belonging to healthy patients (C); smokers (S); and the one including patients subjected to medical treatment and/or having habits that favored $\mathrm{pH}$ alterations, such as taking psychotherapeutic, anti-inflammatory, or chemotherapy drugs, or alcohol (T). After fitting to a linear model using regression analysis, Figure 1 shows the value of the coefficient of determination $\left(R^{2}\right)$ of the fitted regression lines of each group, corresponding to the percentage of variation in the degree of mineralization of the teeth of each group by remineralization processes favored by the presence of factors external to the odontogenesis process. Weak correlations were found in the crown enamel for all groups, and a moderate correlation was only found for $\mathrm{T}$ group in the root cementum.
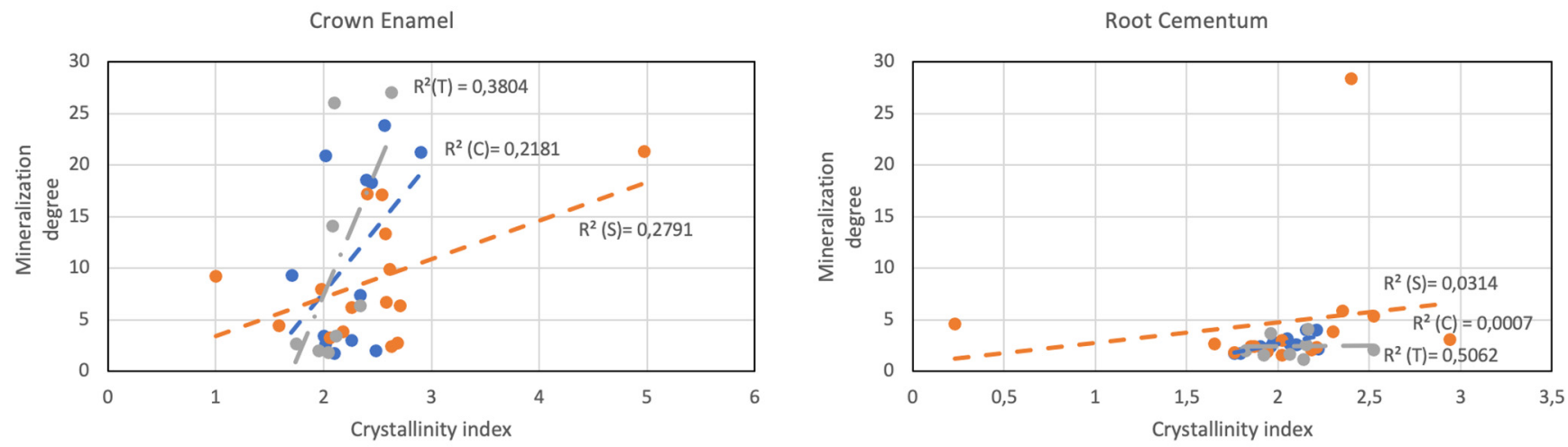

Figure 1. Plots of mineralization degree versus crystallinity index degree for crown enamel and root cementum samples divided into three groups: control (C); smokers (S); and under medical treatment (T) and/or with habits that favored $\mathrm{pH}$ changes.

\subsection{ATR-FTIR Analysis of Selected Samples}

After examination of the vibrational spectra, eight representative samples from each patient group were selected. Their spectra are shown in Figure 2. Two samples corresponded to crown enamel, in order to investigate the possible effect of tobacco and drugs $(\# S M(40) c)$, while taking a sample from a healthy patient $(\# C(33) c)$ as reference for comparison purposes. The remaining six samples, which were from the root cementum zone, were chosen to study the possible effect of the chemical changes caused by tobacco, drugs, and alcohol on teeth. The absorption bands attributable to inorganic phosphate $\left(\mathrm{PO}^{3-}\right)$, at 560,959 , and $1030 \mathrm{~cm}^{-1}$, were associated with bone apatite $\left(v 1, v 3 \mathrm{PO} 4^{3-}\right)$ [39] and hydroxyapatite crystallinity $\left(\vee 4 \mathrm{PO} 4^{3-}\right)$, respectively [40].

Fourier-transform infrared spectroscopic analysis of maturing, poorly crystalline HAP formed from the conversion of amorphous calcium phosphate at constant $\mathrm{pH}$ or variable $\mathrm{pH}$ showed only subtle changes in the $v_{1}, v_{3}$ phosphate absorption region (Figure 3 ). The greater changes were found in smokers treated with psychotherapeutic drugs, followed by patients treated with psychotherapeutic drugs consuming both alcohol and tobacco; whereas the smallest differences were found in smokers that did not consume psychotherapeutic drugs or alcohol. 


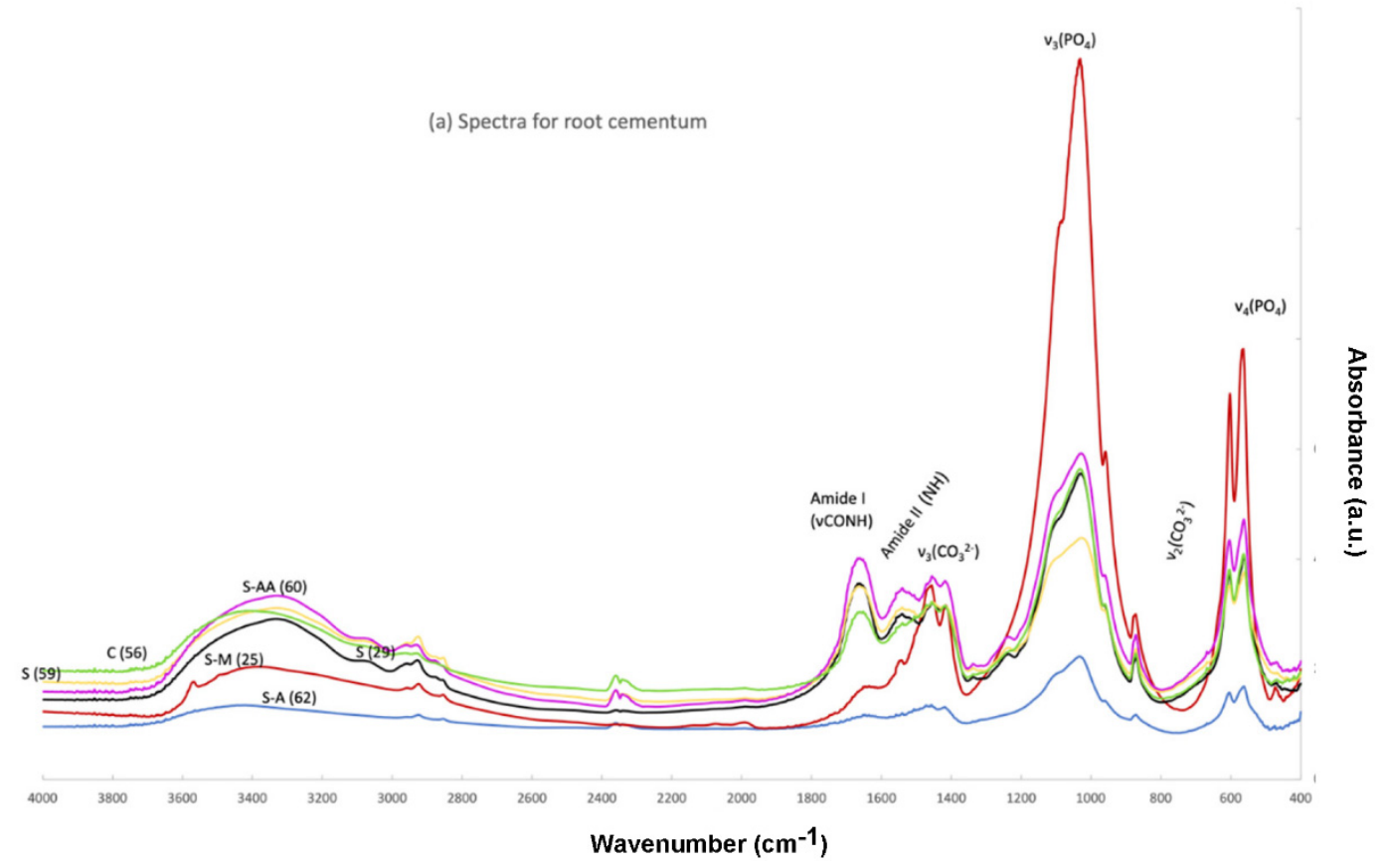

(b) Spectra for crown enamel

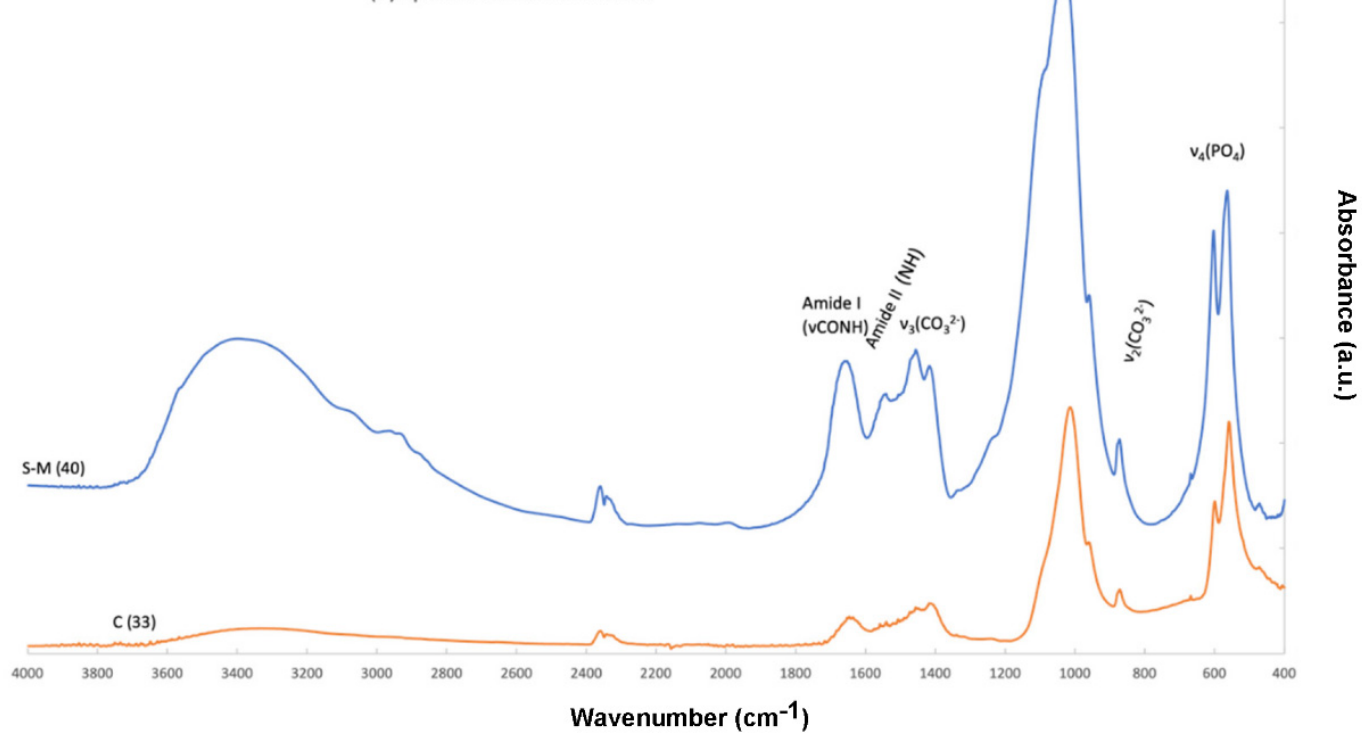

Figure 2. Fourier-transform infrared (FTIR) spectra of selected teeth samples (25- to 62-year-old patients): (a) spectra of root cementum samples; (b) spectra of crown enamel samples. The ranges corresponded to the $v_{2}\left(\mathrm{CO}_{3}{ }^{2-}\right)$ region $\left(850-890 \mathrm{~cm}^{-1}\right), v_{3}\left(\mathrm{CO}_{3}{ }^{2-}\right)$ region $\left(1350-1450 \mathrm{~cm}^{-1}\right), v_{3}\left(\mathrm{PO}_{4}{ }^{3-}\right)$ region (959-1230 cm $\left.\mathrm{cm}^{-1}\right), v_{4}\left(\mathrm{PO}_{4}\right)$ region $\left(550-650 \mathrm{~cm}^{-1}\right)$ and the amide I region $\left(1650-1780 \mathrm{~cm}^{-1}\right)$. The conditions of patients are indicated as follows: alcohol (A); smoker (S); treatment with psychotherapeutic drugs (M); anti-inflammatory drugs (AA); control (C). The age of each patient is shown in parentheses. 


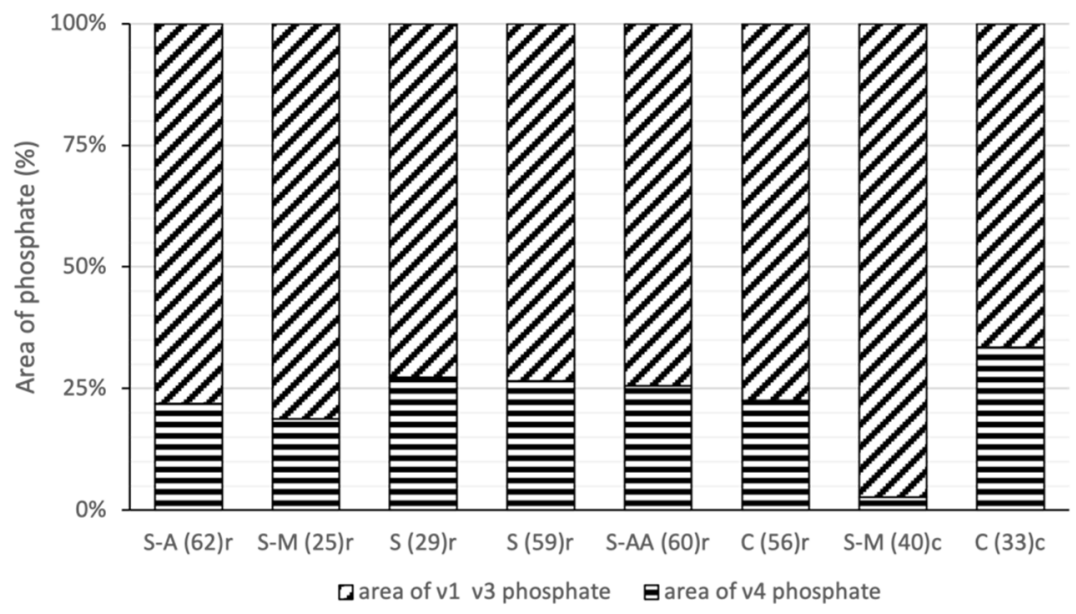

Figure 3. Area of phosphate determined from FTIR spectra. Quantification of phosphate type $v_{1}, v_{3}$ (959-1230 $\left.\mathrm{cm}^{-1}\right)$ and $v_{4}\left(550-650 \mathrm{~cm}^{-1}\right)$. The samples of crown enamel are labeled as "c", and those of root cementum as " $\mathrm{r}$ ". The conditions of patients' teeth are indicated as follows: alcohol (A); smoker (S); treatment with psychotherapeutic drugs (M); anti-inflammatory drugs (AA); control (C). The age of each patient is shown in parentheses.

The infrared spectroscopic analysis of characteristic vibrational bands associated with carbonate substitution pointed to a significant increase in the carbonation degree in smokers (in comparison with control patients) when comparing enamel with root cementum (Figure 4).

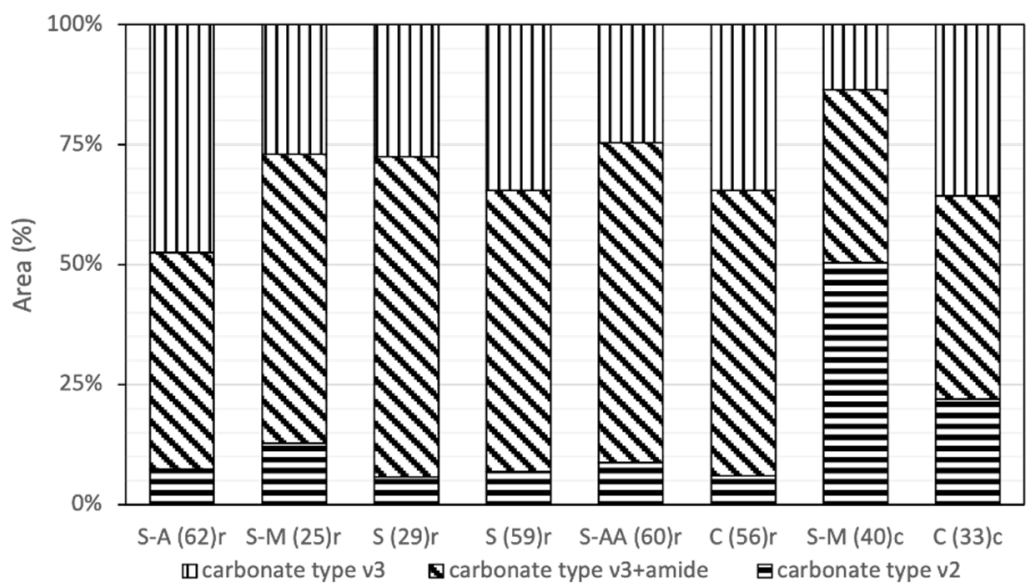

Figure 4. Area of carbonate by FTIR spectra. Quantification of carbonate type $v_{2}\left(850-890 \mathrm{~cm}^{-1}\right), v_{3}$ (a1350-1450 $\left.\mathrm{cm}^{-1}\right)$, and "carbonate type $v_{3}+$ amide" $\left(1450-1600 \mathrm{~cm}^{-1}\right)$. The samples of crown enamel are labeled as "c", and those of root cementum as "r". The conditions of patients' teeth are indicated as follows: alcohol (A); smoker (S); treatment with psychotherapeutic drugs (M); anti-inflammatory drugs (AA); control (C). The age of each patient is shown in parentheses.

This difference in value was lower for the enamel at the crown level than for the root cementum. However, an individual with alcohol and smoking habits showed values with a high degree of carbonation, which also occurred for an individual with smoking habits and under psychotherapeutic drug treatment.

Regarding tobacco consumption, it was possible to observe that type A carbonate was more altered in younger patients. Likewise, Figure 4 shows that the proportion of type $\mathrm{B}$ apatite was higher than that of type $\mathrm{A}$ in the patient who was being medicated with psychotherapeutic drugs $(\# \operatorname{SM}(40) \mathrm{c})$, which showed that there was a turnover in his/her 
oral cavity faster than in any other situation. In this same patient, $\# S M(40) c$, the carbonate type A content was relatively high.

Likewise, the peaks corresponding to amide II (-CO-NH-) and amide I (-CO-NH groups of peptide bonds can be observed in Figure 2, as previously described by Ramakrishnaiah et al. [27]. The amide band I was representative of the secondary structure of proteins. In the spectra, a similar profile was observed for all the analyzed samples, except for those from an elderly patient (\#SA(62)r) and from a patient subjected to valproic acid ingestion (\#SM(25)r).

\subsection{Crystallographic Conservation of Enamel and Cementum}

To assess and compare the crystalline structures of the six samples from root cementum and two from enamel, XRPD characterization was used. Figure 5 shows the X-ray powder diffraction patterns of the same eight samples previously analyzed by FTIR. The main phases in the hydroxyapatite's X-ray powder diffraction pattern [41] are indicated in Figure 4 on the diffractogram of the most crystalline sample, \#C(33)c.

The interpretation of the diffractograms showed similarities among the control samples, $\# C(33) c$ and $\# C(56) r$, for enamel and root, respectively. The diffractogram of the sample of crown enamel taken as a control $(\# C(33) \mathrm{c})$ showed its strongest peaks at $2 \theta$ $=31.8^{\circ}, 32.3^{\circ}$, and $33.0^{\circ}$, corresponding to hydroxyapatite crystal (002), (102), and (210) reflection planes, respectively.

The crystallinity degree was determined for all the samples in the $20-70^{\circ}$ range, in agreement with Behroozibakhsh et al. [38], finding crystallinity index values in the 73.5-85.4\% range, with the lowest value for \#SM(25)r and the highest value for \#C(33)c.

Albeit less well defined, the peaks associated with HAP appeared in the diffraction patterns of all samples, regardless of the different clinical records. Nonetheless, in the $\# S(59) r$ sample, two peaks at $2 \theta=34.8^{\circ}$ and $35.7^{\circ}$ also were observed. The former was suggestive of the presence of an unusual form of calcium phosphate called whitlockite. In periodontal dentistry, whitlockite phosphate is one of the inorganic components of dental calculi and salivary stones. In relation to the peak at $2 \theta=35.7^{\circ}$, it was tentatively ascribed to $\mathrm{Al}_{2} \mathrm{O}_{3}$ or, preferably, to a poly-methyl methacrylate-based dental restorative [42].

\subsection{Surface Morphology and Ca/P Ratios}

Figure 6 shows the micrographs of the selected crown enamel and root cementum samples, representative of each group of patients under study. Clear differences were observed between the surfaces of the two regions of the tooth under study. At low magnification $(400 \times)$, the presence of aprismatic enamel and perikymata could be observed, suggesting that the physiological structure was preserved. The areas adjacent to plough furrows (those obtained during the filing process to release the previously analyzed dust) indicated the arrangement pattern of HAP crystallites [43]. 
(a)

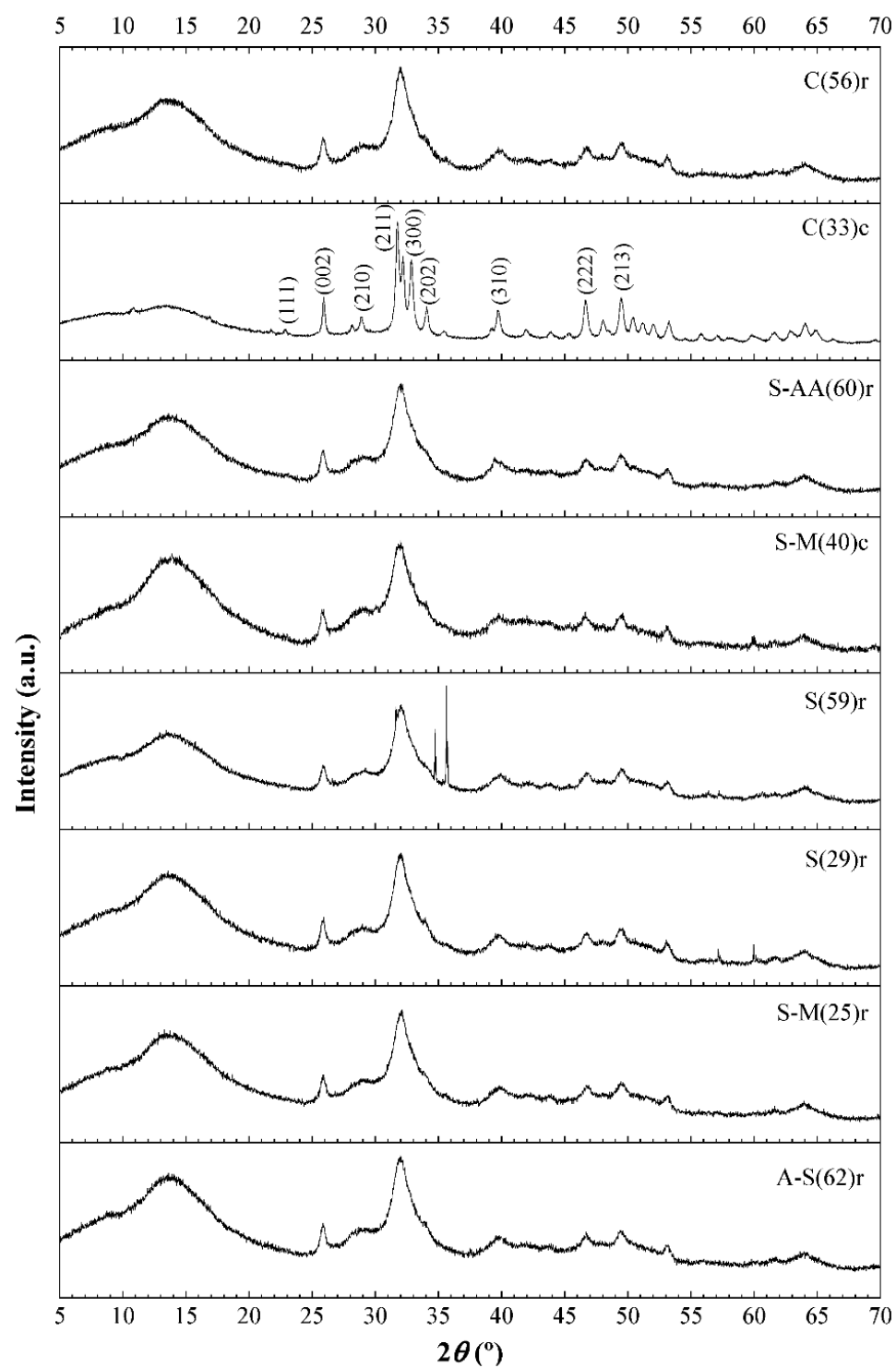

(b)

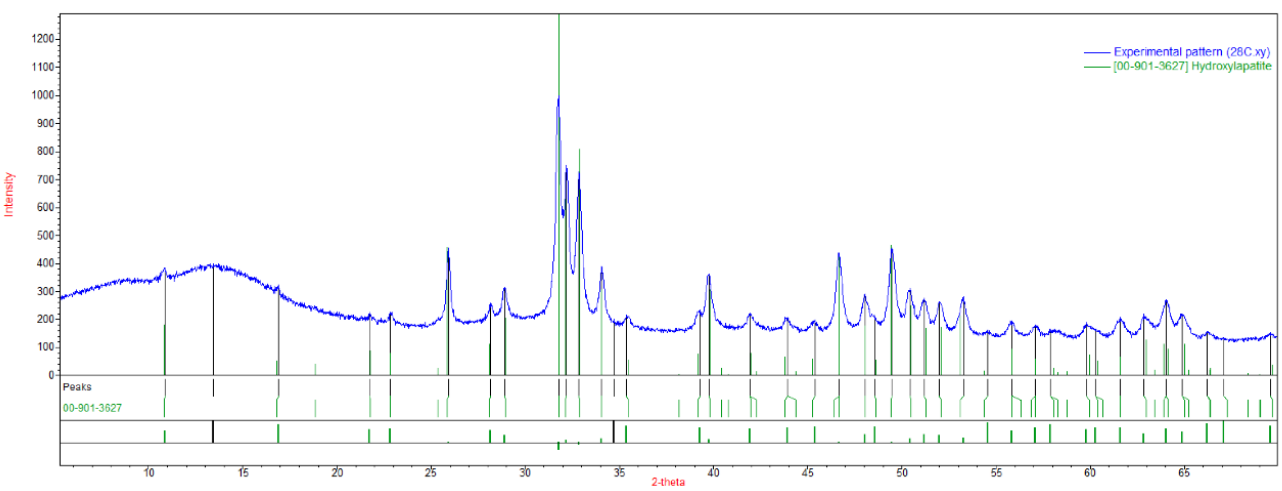

Figure 5. (a) Dffractograms of enamel from crown (" $c$ ") and tooth root cementum (" $r$ "). The conditions of patients' teeth are indicated as follows: alcohol (A); smoker (S); treatment with psychotherapeutic drugs (M); anti-inflammatory drugs (AA); control (C). The age of the patient is shown in parentheses. (b) Comparison of the X-ray powder diffraction patterns of the $\# \mathrm{C}(33) \mathrm{c}$ sample and hydroxyapatite. 


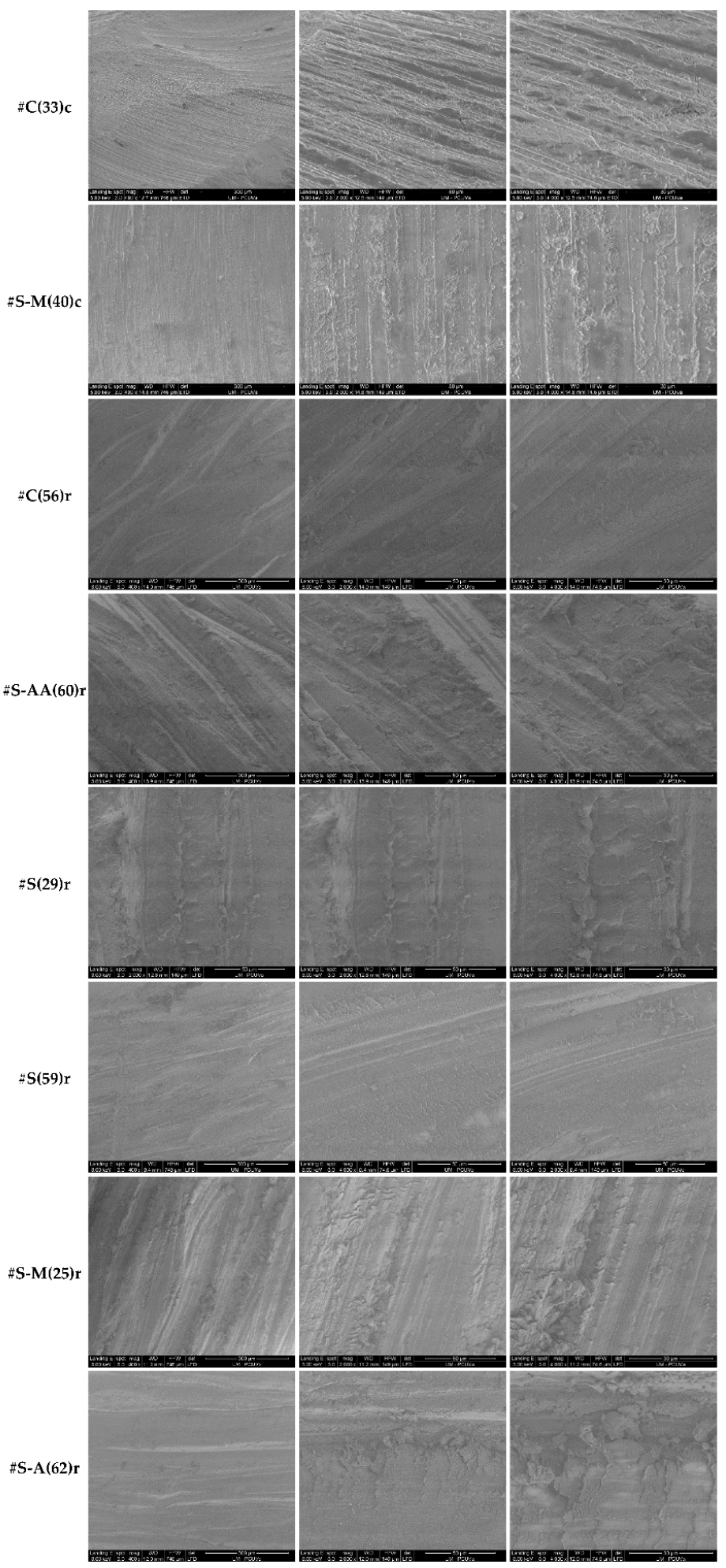

Figure 6. Scanning electron micrographs of a representative crown enamel (" $c$ ") and root cementum $\left("{ }^{\prime \prime}\right)$ samples at increasing magnifications (from left to right). The conditions of patients' teeth are indicated as follows: alcohol (A); smoker (S); treatment with psychotherapeutic drugs (M); anti-inflammatory drugs (AA); control (C). The age of the patient is shown in parentheses.

Concerning the surface elemental composition results, $\mathrm{Ca}$ and $\mathrm{P}$ contents (Table 2) could be used to gain insight into the mineralization degree. According to Tzaphlidou et al. [44], their ratio may offer higher reliability for the diagnosis of bone disorders due to its 
specificity. The \#SA(62)r and S(59)r samples showed the lowest $\mathrm{Ca} / \mathrm{P}$ ratios $(\simeq 1.7)$, followed by sample \#SM(25)r $(\mathrm{Ca} / \mathrm{P}$ ratio = 1.97). These values were substantially lower than those found for the control samples $(\mathrm{Ca} / \mathrm{P}$ ratio $\simeq 2.4$ for $\# \mathrm{C}(33) \mathrm{c}$ and $\# \mathrm{C}(56) \mathrm{r})$, in excellent correspondence with what was expected for single-phased apatitic calcium phosphate, $\mathrm{Ca}_{10-\mathrm{x}}\left(\mathrm{PO}_{4}\right)_{6-\mathrm{x}}\left(\mathrm{HPO}_{4}\right)_{\mathrm{x}}(\mathrm{OH})_{2-\mathrm{x}}[45]$. The high $\mathrm{Ca} / \mathrm{P}$ ratios $(\simeq 3.1)$ in samples \#SM $(40) \mathrm{C}$ and \#SAA(60)r were unusual for teeth, and could have been the result of the presence of bone fat, lipids, or marrow, which have been reported to account for a $5-10 \%$ increase in the $\mathrm{Ca} / \mathrm{P}$ ratio [44].

Table 2. Calcium and phosphorus contents of the eight selected crown enamel and root samples from EDS analyses. The reported values (expressed in \%) were obtained at a $4000 \times$ magnification.

\begin{tabular}{ccccccccc}
\hline Sample & \#C(33)c & \#S-M(40)c & \#C(56)r & \#S-AA(60)r & \#S(29)r & \#S(59)r & \#S-M(25)r & \#S-A(62)r \\
\hline $\mathrm{Ca}$ & 37.24 & 50.7 & 32.96 & 42.68 & 37.18 & 25.61 & 25.5 & 27.48 \\
$\mathrm{P}$ & 15.59 & 15.8 & 13.97 & 13.9 & 15.54 & 15.35 & 12.93 & 16.2 \\
$\mathrm{Ca} / \mathrm{P}$ & 2.39 & 3.21 & 2.36 & 3.07 & 2.39 & 1.67 & 1.97 & 1.70 \\
\hline
\end{tabular}

\section{Discussion}

Drug use may affect the oral cavity, depending on the type and dose of the substance consumed, the time and frequency of use, and the individual characteristics of the user. The enamel and cementum of the teeth are considered highly mineralized tissues in the human body [46], hydroxyapatite being the main inorganic component of the teeth (although other mineral species are incorporated throughout the life of the tooth) [6]. Along with genetics, external factors such as medical treatments, coupled with nutrition during the tooth development period, can influence the chemical content of the crown enamel [47].

On the other hand, saliva plays an active role in maintaining the balance of electrolytes in the oral cavity. Its composition is affected by multiple factors, such as alcohol intake, drug use, or physical activity. Likewise, saliva is responsible for forming a film on the hard and soft parts of the oral cavity, thus protecting and maintaining moisture [48]. Teeth are subjected to mineralization/remineralization processes throughout their life, a continuous but variable cycle that repeats itself with food intake and is unique for each person [10].

In this study, we compared the changes in inorganic components of teeth from patients with different clinical records by spectroscopic techniques. The effect of different external factors in the process of remineralization of the tooth was investigated. Therefore, samples corresponding to the crown enamel and root cementum areas with different exposure to these oral fluids were analyzed. The external factors for the oral cavity considered were age, habits, and diseases, giving rise to six different groups plus a control group consisting of patients with healthy habits. Table 1 summarizes the chemical structure of crown enamel and root cementum, as determined by ATR-FITR spectroscopy, of 36 dental samples to evaluate the deleterious effect of the mentioned external factors.

When the values obtained for the crystallinity index, together with the degree of mineralization and carbonation (parameters involved in the quality of the mineral of the teeth and that often evolve concomitantly), were analyzed, it was observed that they were not equivalent, and corresponded to different entities. No apparent relationship was found with the patients' age or sex.

In order to gain insight into the remineralization process in acidic environments generated by factors external to the tooth, eight samples were selected while considering their infrared vibrational profile, two from the crown part $(\# C(33) c$ and $\# S M(40) c)$ and six from the root (\#C(56)r, \#SM(25)r, \#SAA(60)r, \#AS(62)r, \#S(29)r, and \#S(59)r). The spectral changes observed (Figure 2) in those eight samples was attributed to alterations induced by the demineralization of the morphology and/or orientation of the microcrystals of the analyzed samples. In a previous study by Shellis et al. [22], the authors reported that the enamel dissolution in acidic environments occurred due to the interaction of hydrogen ions with hydroxyapatite crystals. Thus, while the enamel interacted with saliva and the oral 
film, the cementum in the root did so with the internal maxillary artery, being able to favor their repair by allowing ionic exchange with them.

The role of calcium and phosphate ions is relevant to keeping the tooth healthy and favoring the occurrence of different remineralizations in the tooth structure. Our findings in phosphate groups of hydroxyapatite (Figure 2) showed changes in the intensity of the band at $1030 \mathrm{~cm}^{-1}$, attributable to small changes that occurred in the chemical composition of the crown samples in relation to those of the root cementum of the teeth. The band assigned to the $v_{4} \mathrm{PO}_{4}^{3-}$ vibration was shown to be useful in the analysis of the crystallinity of apatite, while the $v_{3}$ and $v_{1}$ modes of phosphate $\left(959-1230 \mathrm{~cm}^{-1}\right)$ turned out to be the best markers to detect the structural changes experienced. That situation appeared to be exemplified (Figure 3) when the enamel of the smoker patient treated with antipsychotic medication (\#SM(40)c) was compared with that of \#C(33)c control tooth, the proportion of vibrational modes $v_{1}, v_{3} \mathrm{PO}_{4}{ }^{3-}$ being the majority with respect to $v_{4} \mathrm{PO}_{4}{ }^{3-}$ (absorption independent of the organic matrix of the sample). Regarding root cementum, the alteration by external factors was potentially lower, because it is protected (by connective tissues) from these variations (mainly, $\mathrm{pH}$ ). However, in our casuistry, we found an effect entirely prone to favoring structural change in hydroxyapatite crystals, such as psychotherapeutic medication. Therefore, the active process of remineralization was superior in those patients who were under this medical prescription. As it can be observed in Figure 3, the analysis of the vibrational modes corresponding to $v_{1}, v_{3} \mathrm{PO}_{4}{ }^{3-}$ in the analyzed root cementum samples suggested that the ingestion of psychotherapeutic medication (\#SM(25)r) was the most influential external factor. According to Penel et al. [49], the domain corresponding to the phosphate $v_{3}$ mode was the most affected by carbonate substitution.

The carbonate ions incorporated into the apatite network are easily detectable by FTIR, as revealed by Rey et al. [50]. In Figure 2, one may observe the vibrational modes between $1400 \mathrm{~cm}^{-1}$ and $1600 \mathrm{~cm}^{-1}$ and that of the $v_{3} \mathrm{CO}_{3}{ }^{2-}$ domain (carbonate type A), superimposed on the protein absorption bands; and that of the $v_{3} \mathrm{CO}_{3}{ }^{2-}$ mode, with absorption at $872 \mathrm{~cm}^{-1}$ (carbonate type $\mathrm{B}$ ), superimposed on that of $v_{3} \mathrm{PO}_{4}{ }^{3-}$, in agreement with the findings of Leventouri et al. [51].

As shown in Figure 4, the intensity of the absorption band attributable to type B carbonate was the most susceptible to variation due to external agents. When the intensities of the carbonate bands were compared, it was observed that the carbonate type B bands were lower in the root cementum than in the enamel of the crown. Its content was more affected in teeth that were subjected to medical treatments received (case in which the fluids present in the oral cavity played an important role in damping $\mathrm{pH}$ variations and in the replacement of inorganic ions, minimizing any alteration). As it was verified in the six patients considered in comparison with the control patients, the presence of type $v_{3}$ carbonate decreased with psychotherapeutic medication, tobacco, and alcohol. However, in the root cementum sample \#SA(62)r, corresponding to a tooth from an older adult smoker with a habit of drinking alcohol, the presence of $v_{3} \mathrm{CO}_{3}{ }^{2-}$ was higher than that in the other analyzed samples (Figure 4). This finding can be explained by the concurrence, in this particular case, of multiple external factors, determining a higher degree of carbonation of the enamel as compared to that of the remaining samples analyzed (Table 1), an effect resulting from the severe distortions in the structure of dental hydroxyapatite. Likewise, in the \#SM(40)c sample, the proportion of type A carbonate was higher than that of type $\mathrm{B}$, a fact that can be explained based on the composition of saliva as a biological fluid that bathes the oral cavity and that contains electrolytes such as sodium, potassium, chloride, and bicarbonate ions that can be exchanged.

The presence of proteins/enzymes (amide groups) (Figure 4) was relatively high in the root of the teeth of young smokers (\#S(29)r) and smokers under treatment with antiinflammatory medication (\#SAA(60)r). As stated by Malhotra et al. [52], tobacco reduces blood flow to the connective tissue that is part of the gums, depriving them of oxygen and nutrients, leaving them vulnerable to bacterial infections. For this reason, the differences in content in amide groups of the root of the teeth of the aforementioned patients compared 
to those of the control patient were higher than in the samples of root cementum, which, despite being a hard tissue, is the one that is most in contact with the connective tissue. The decrease in the amide I group amount related to the protein denaturation was previously described by Kong and Yu [53].

When we compared the content of carbonate type $v_{2}$ in sample \#SM(40)c (Figure 4) with that of phosphate $v_{1}, v_{3}$ (Figure 3 ), it was possible to observe an increase in the deposits of young minerals of biological apatite in the crown with respect to the control patient $\# C(33) c$, at the same time that there was a higher proportion of carbonates replacing $\mathrm{OH}^{-}$ ions in the apatite structure [54]. This was due to the fact that the tooth exposed to an acidic medium had a more hydrated coverage, with a greater susceptibility to ionic exchange with salivary fluids and with a higher proportion of carbonate B. In this regard, several authors have shown that the acid concentration affected the dissolution rate of the crown enamel, especially in the 2.45-3.2 pH range [22], and that the ingestion of acidic drinks or with the ability to maintain a low $\mathrm{pH}$ favored the erosion of teeth [55].

On the contrary, the dissolution of hydroxyapatite in dentin can take place at any $\mathrm{pH}$ [22]. This is a consequence of the existence, in the enamel crystal lattice, of intercrystalline spaces that constitute possible diffusion routes [56], a feature entirely consistent with the low crystallinity index observed for sample \#SM(40)c (Table 1). It was evident that some psychotherapeutic drugs negatively affected calcium balance, in the same way that excessive consumption of tobacco altered its retention, both being important considerations when trying to maintain the good mineralization of the tooth.

Therefore, the subsequent remineralization process, taking place either on the surface or inside the partially demineralized enamel, will occur with precipitation of calcium, phosphate and other ions. These ions present in oral fluids can come from the dissolution of mineralized tissue, originating from an external source as long as the $\mathrm{pH}$ is neutral. Another case is the root cementum of the tooth, a thin layer with properties similar to those of bone that covers the root of the tooth and that is surrounded by the periodontal ligament, which is less exposed to these remineralization phenomena.

Regarding the analysis of the crystallinity of the samples in Figure 2, in view of the degree of definition of the peaks in the diffractograms (Figure 5), the crystallinity index values were in the $73.5-85.4 \%$ range, in such a way that the highest crystallinity was observed in a control sample $(\# C(33) c)$, and the sample from a patient undergoing medical treatment \#SM(25)r was the least crystalline. A high index obtained by XRPD was related to the size of the crystal in the sample and the degree of order within the crystals. On the other hand, the CI obtained from FTIR (Table 1) was related to the degree of geometric deformation of the molecular bonds within them. Thus, in sample \#C(33)c, crystals would be less deformed, whereas the external factors considered in our study would have favored diagenetic changes as a consequence of recrystallization processes, leading to the presence of smaller crystals, such as those observed in teeth exposed to alcohol intake (\#AS(62)r) and/or smoking habits (\#S(29)r, \#S(59)r), as well as to psychotherapeutic drugs (\#SM(40)c, \#SAA(60)r). The sensitivity of the XRPD technique was demonstrated in our analysis by detecting the presence in sample \#S(59)r of an unusual form of calcium phosphate called whitlockite, a component associated with dental calculi and salivary stones. It is also worth noting that our observations were aligned with the results obtained by Reyes-Gasga et al. [57], who already warned that the information obtained from the CIs of teeth by FTIR was in some cases contradictory to that obtained by powder diffractograms.

In our analysis, the relationship between age and the crystallinity index had less influence than those external factors that favored an ion exchange process with hydroxyapatite crystals. However, in patients treated with psychotherapeutic drugs, and due to the total oral absorption of this type of drug, the root cementum samples showed a greater affectation than those of crown enamel.

SEM analysis allowed us to obtain information on the morphology of the enamel and root cementum. The micrographs in Figure 6 did not reveal any obvious effect of drug ingestion, which suggested that the remineralization process developed rapidly and 
homogeneously from its initial form, due to the rapid flow of $\mathrm{Ca}$ and $\mathrm{PO}_{4}$ ions occupying the space formed as water and mineral salts were lost.

Regarding the EDS results, it has been stated that the $\mathrm{Ca} / \mathrm{P}$ ratio changes as a function of the mineralization degree, in such a way that it may be used as an indicator of the remineralization degree. Nonetheless, in the present study, no clear patterns associated with smoking, medication, or age were observed using this technique (in fact, it is worth noting that sample $\# S(29)$ r, from a young smoker, showed a $\mathrm{Ca} / \mathrm{P}$ ratio similar to those of control samples).

\section{Conclusions}

ATR-FTIR spectroscopy allowed us to quantify the concentration of the phosphate group in hydroxyapatite, as well as to identify its crystallinity characteristics, in order to determine the degree of mineralization of the crown enamel and root cementum in a casuistry determined by various external factors. The intensity of the absorption band corresponding to inorganic phosphate was found to increase in patients undergoing treatment with psychotherapeutic drugs and, in enamel, the remineralization process was found to be more active than in the root cementum due to direct contact with saliva. As regards the analysis of other functional groups, the results showed that the intensity of the absorption band of the amide group decreased both with the treatment with psychoactive substances and with the biological age of the patient. Further, with respect to the carbonate group, it was evidenced that in the area of the tooth that was in contact with vascularized tissue, such as the root, type A carbonate was the one that underwent the greatest alterations, especially in the teeth of patients undergoing analgesic and psychotherapeutic drug treatments, even higher than that observed with the ingestion of alcohol in elderly patients. With regard to the CI values, although CI data obtained by FTIR was not directly comparable with CI data obtained by XRPD and vice versa, it was noticed that the highest $C I$ values were found in smoking patients. SEM and EDS data were not elucidative in terms of differentiating between the different groups of patients. From a comparison among the various techniques used, it was concluded that ATR-FTIR holds promise in dentistry research areas as a fast, reliable, and cost-effective way to study the effect of changes produced in the hydroxyapatite structure in teeth and, consequently, to determine possible strategies in the diagnostic protocol.

Author Contributions: Conceptualization, M.Á.R, M.G. and J.M.-G.; methodology, C.D. and J.M.-G.; formal analysis, M.Á.R., J.M.-G., P.M.-R. and D.C.-D.; investigation, C.D., M.Á.R., J.M.-G., P.M.-R., M.G. and D.C.-D.; writing-original draft preparation, M.Á.R., J.M.-G., P.M.-R., M.G., and D.C.-D.; writing-review and editing, M.Á.R., J.M.-G., P.M.-R., M.G. and D.C.-D. All authors have read and agreed to the published version of the manuscript.

Funding: This research received no external funding.

Data Availability Statement: The data presented in this study are available on request from the corresponding author.

Acknowledgments: The authors gratefully acknowledge the staff and patients of Clínica Universitaria of European University Miguel Cervantes (UEMC) and Diez-Arauz's clinics for their support in the collection of the teeth, as well as Alberto Santiago Aliste, from the Unidad de Microscopía of the Parque Científico of the University of Valladolid (UVA), who conducted the HR-SEM measurements.

Conflicts of Interest: The authors declare no conflict of interest.

\section{References}

1. Sweet, D. Forensic dental identification. Forensic Sci Int. 2010, 201, 3-4. [CrossRef]

2. Pretty, I.A.; Sweet, D. A look at forensic dentistry-Part I. The role of teeth in the determination of human identity. Br. Dent. J. 2001, 190, 359-366. [CrossRef]

3. Krishan, K.; Kanchan, T.; Garg, A.K. Dental Evidence in Forensic Identification-An Overview, Methodology and Present Status. Open Dent. J. 2015, 9, 250-256. [CrossRef] 
4. Tinoco, R.L.; Martins, E.C.; Daruge, E., Jr.; Daruge , E.; Prado , F.B. ; Caria , P.H. Dental anomalies and their value in human identification: A case report. J. Forensic Odontostomatol. 2010, 28, 39-43. [PubMed]

5. Gupta, P.; Kaur, H.; Shankari, G.S.; Jawanda, M.; Sahi, N. Human age estimation from tooth cementum and dentin. J. Clin. Diagn. Res. 2014, ZC8, 7-10. [CrossRef]

6. Combes, C.; Cazalbou, S.; Rey, C.C. Apatite Biominerals. Minerals 2016, 6, 34. [CrossRef]

7. Lacruz, R.S.; Habelitz, S.; Wright, J.T.; Paine, M.L. Dental enamel formation and implications for oral health and disease. Physiol. Rev. 2017, 97, 939-993. [CrossRef]

8. Simmer, J.P.; Hu, J.C. Dental enamel formation and its impact on clinical dentistry. J. Dent. Educ. 2001, 65, 896-905. [CrossRef] [PubMed]

9. Abou Neel, E.A.; Aljabo, A.; Strange, A.; Ibrahim, S.; Coathup, M.; Young, A.M.; Bozec, L.; Mudera, V. Demineralizationremineralization dynamics in teeth and bone. Int. J. Nanomed. 2016, 11, 4743-4763. [CrossRef]

10. Hayashi, O.; Chiba, T.; Shimoda, S.; Momoi, Y. Demineralization and Remineralization Phenomena of Human Enamel in Acid Erosion Model. J. Hard Tissue Biol. 2016, 25, 27-34. [CrossRef]

11. Al Shehab, A.H.; Al Hazoom, A.A,; Alowa, M.H.; Al Ali, H.A.; Abdulmohsen, A.A.; Farooq, I. Effect of bristle stiffness of manual toothbrushes on normal and demineralized human enamel-An in vitro profilometric study. Int. J. Dent. Hyg. 2018, 16, e128-e132. [CrossRef]

12. Shamim, T.; Ipe Varghese, V.; Shameena, P.M.; Sudha, S. Age estimation: A dental approach. JPAFMAT 2006, 6, $14-16$.

13. Verma, M.; Verma, N.; Sharma, R.; Sharma, A. Dental age estimation methods in adult dentitions: An overview. J. Forensic Dent. Sci. 2019, 11, 57-63. [CrossRef] [PubMed]

14. Nanci, A. Ten Cate's Oral Histology: Development, Structure, and Function, 9th ed.; Mosby: Maryland Heights, MO, USA, 2008.

15. Bodart, F.; Deconninck, G.; Martin, M.T. Large scale study of tooth enamel. IEEE Trans. Nucl. Sci. 1981, 28, 1401-1403. [CrossRef]

16. Gelse, K.; Pöschl, E.; Aigner, T. Collagens-structure, function, and biosynthesis. Adv. Drug Deliv. Rev. 2003, 55, 1531-1546. [CrossRef] [PubMed]

17. Vallet-Regí, M.; González-Calbet, J.M. Calcium phosphates as substitution of bone tissues. Prog. Solid State Chem. 2004, 32, 1-31. [CrossRef]

18. Eanes, E.D. Enamel apatite: Chemistry, structure and properties. J. Dent. Res. 1979, 58, 829-836. [CrossRef]

19. Elliot, J.C.; Holcomb, D.W.; Young, R.A. Infrared determination of the degree of substitution of hydroxyl by carbonate ions in human dental enamel. Calcif. Tissue Int. 1985, 37, 372-375. [CrossRef]

20. Pasteris, J.; Wopenka, B.; Valsami-Jones, E. Bone and Tooth Mineralization: Why Apatite? Elements 2008, 4, 97-104. [CrossRef]

21. Mathew, M.; Takagi, S. Structures of Biological Minerals in Dental Research. J. Res. Natl. Inst. Stand Technol. 2001, 106, 1035-1044. [CrossRef] [PubMed]

22. Shellis, R.P.; Barbour, M.E.; Jones, S.B.; Addy, M. Effects of $\mathrm{pH}$ and acid concentration on erosive dissolution of enamel, dentine, and compressed hydroxyapatite. Eur. J. Oral Sci. 2010, 118, 475-482. [CrossRef] [PubMed]

23. Cummins, D. The development and validation of a new technology, based upon $1.5 \%$ arginine, an insoluble calcium compound and fluoride, for everyday use in the prevention and treatment of dental caries. J. Dent. 2013, 41 (Suppl. S2), S1-S11. [CrossRef]

24. Farooq, I.; Bugshan, A. The role of salivary contents and modern technologies in the remineralization of dental enamel: A narrative review. F1000Research 2020, 9, 171. [CrossRef]

25. Vainionpaa, R.; Tuulaniemi, K.; Pesonen, P.; Laitala, M.-L.; Anttonen, V. Erosive tooth wear and use of psychoactive substances among Finnish prisoners. BMC Oral Health 2019, 19, 97. [CrossRef] [PubMed]

26. Bachmann, L.; Diebolder, R.; Hibst, R.; Zezell, D.M. Infrared absorption bands of enamel and dentin tissues from human and bovine teeth. Appl. Spectrosc. Rev. 2003, 38, 1-14. [CrossRef]

27. Ramakrishnaiah, R.; Rehman, G.U.; Basavarajappa, S.; Al Khuraif, A.A.; Durgesh, B.H.; Khan, A.S.; Rehman, I. Applications of Raman spectroscopy in dentistry: Analysis of tooth structure. Appl. Spectrosc. Rev. 2015, 50, 332-350. [CrossRef]

28. Movasaghi, Z.; Rehman, S.; Rehman, I. Fourier Transform Infrared (FTIR) Spectroscopy of Biological Tissues. Appl. Spectrosc. Rev. 2008, 43, 134-179. [CrossRef]

29. France, C.; Sugiyama, N.; Aguayo, E. Establishing a preservation index for bone, dentin, and enamel bioapatite mineral using ATR-FTIR. J. Archaeol. Sci. Rep. 2020, 33, 102551. [CrossRef]

30. Tramini, P.; Bonnet, B.; Sabatier, R.; Maury, L. A method of age estimation using Raman microspectrometry imaging of the human dentin. Forensic Sci. Int. 2001, 118, 1-9. [CrossRef]

31. Krafft, C.; Sergo, V. Biomedical applications of Raman and infrared spectroscopy to diagnose tissues. Spectroscopy 2006, 20, 195-218. [CrossRef]

32. Liu, Y.; Yao, X.; Liu, Y.W.; Wang, Y. A Fourier Transform Infrared spectroscopy analysis of carious dentin from transparent zone to normal zone. Caries Res. 2014, 48, 320-329. [CrossRef] [PubMed]

33. Karteva, E.; Manchorova, N. Root Dentin Analysis from using Fourier-Transform Infrared Spectroscopy with Attenuated Total Reflectance (FTIR-ATR). IJRS 2019, 8. [CrossRef]

34. Grunenwald, A.; Keyser, C.; Sautereau, A.M.; Crubézy, E.; Ludes, B.; Drouet, C. Revisiting carbonate quantification in apatite (bio)minerals: A validated FTIR methodology. J. Archaeol. Sci. 2014, 49, 134-141. [CrossRef]

35. Shepel, D.; Goreacioc, T.; Lupascu, T.; Filippov, M.; Rusu, M. Method of Infrared Spectra Registration of Activated Carbons in Potassium Bromide Pellets. Chem. J. Mold. 2015, 10, 113-115. [CrossRef] 
36. Miller, L.M.; Vairavamurthy, V.; Chance, M.R.; Mendelsohn, R.; Paschalis, E.P.; Betts, F.; Boskey, A.L. In situ analysis of mineral content and crystallinity in bone using infrared micro-spectroscopy of the $\mathrm{PO}_{4}{ }^{3-}$ vibration. Biochim. Biophys. Acta 2001, 1527, 11-19. [CrossRef]

37. Boskey, A.L.; Mendelsohn, R. Infrared spectroscopic characterization of mineralized tissues. Vib. Spectrosc. 2005, 38, 107-114. [CrossRef]

38. Behroozibakhsh, M.; Hajizamani, H.; Shekofteh, K.; Otadi, M.; Ghavami-Lahiji, M.; Nazari, N.S.F. Comparative assessment of the crystalline structures of powder and bulk human dental enamel by X-ray diffraction analysis. J. Oral Biosci. 2019, 61, 173-178. [CrossRef]

39. Paschalis, E.P.; DiCarlo, E.; Betts, F.; Sherman, P.; Mendelsohn, R.; Boskey, A.L. FTIR microspectroscopic analysis of human osteonal bone. Calcif. Tissue Int. 1996, 59, 480-487. [CrossRef]

40. Rey, C.; Shimizu, M.; Collins, B.; Glimcher, M.J. Resolution-enhanced Fourier transform infrared spectroscopy study of the environment of phosphate ions in the early deposits of a solid phase of calcium-phosphate in bone and enamel, and their evolution with age. I: Investigations in the upsilon ${ }_{4} \mathrm{PO}_{4}$ domain. Calcif. Tissue Int. 1990, 46, 384-394. [CrossRef]

41. Young, R.A.; Mackie, P.E. Crystallography of human tooth enamel: Initial structure refinement. Mater. Res. Bull. 1980, 15, 17-29. [CrossRef]

42. Alghunaim, N.S. In situ synthesis and investigation poly (methyl methacrylate)/ polycarbonate nanocomposites incorporated with copper oxide nanoparticles. Results Phys. 2020, 19, 103368. [CrossRef]

43. Zhang, X.; Li, Y.; Sun, X.; Kishen, A.; Deng, X.; Yang, X.; Wang, H.; Cong, C.; Wang, Y.; Wu, M. Biomimetic remineralization of demineralized enamel with nano-complexes of phosphorylated chitosan and amorphous calcium phosphate. J. Mater. Sci. Mater. Med. 2014, 25, 2619-2628. [CrossRef] [PubMed]

44. Tzaphlidou, M.; Zaichick, V. Calcium, phosphorus, calcium-phosphorus ratio in rib bone of healthy humans. Biol. Trace Elem. Res. 2003, 93, 63-74. [CrossRef]

45. Bailey, M.J.; Coe, S.; Grant, D.M.; Grime, G.W.; Jeynes, C. Accurate determination of the Ca:P ratio in rough hydroxyapatite samples by SEM-EDS, PIXE and RBS-a comparative study. X-ray Spectrom. 2009, 38, 343-347. [CrossRef]

46. Ten Cate, A.R. Oral Histology, Development. Structure, and Function, 4th ed.; Mosby: St. Louis, MO, USA, 1994.

47. Allan, J.H. Investigations into the mineralization pattern of human dental enamel. J. Dent. Res. 1959, 38, 1096-1128. [CrossRef]

48. Kubala, E.; Strzelecka, P.; Grzegocka, M.; Lietz-Kijak, D.; Gronwald, H.; Skomro, P.; Kijak, E. A Review of Selected Studies That Determine the Physical and Chemical Properties of Saliva in the Field of Dental Treatment. Biomed Res. Int. 2018, $2018,6572381$. [CrossRef]

49. Penel, G.; Leroy, G.; Rey, C.; Sombret, B.; Huvenne, J.P.; Bres, E. Infrared and Raman microspectrometry study of fluor-fluorhydroxy and hydroxy-apatite powders. Mater. Sci. Mater. Med. 1997, 8, 271-276. [CrossRef]

50. Rey, C.; Shimizu, M.; Collins, B.; Glimcher, M.J. Resolution-enhanced Fourier transform infrared spectroscopy study of the environment of phosphate ion in the early deposits of a solid phase of calcium phosphate in bone and enamel and their evolution with age: 2 . Investigations in the $\mathrm{nu}_{3} \mathrm{PO}_{4}$ domain. Calcif. Tissue Int. 1991, 49, 383-388. [CrossRef]

51. Leventouri, T.; Antonakos, A.; Kyriacou, A.; Venturelli, R.; Liarokapis, E.; Perdikatsis, V. Crystal structure studies of human dental apatite as a function of age. Int. J. Biomater. 2009, 2009, 698547. [CrossRef]

52. Malhotra, R.; Kapoor, A.; Grover, V.; Kaushal, S. Nicotine and periodontal tissues. J. Indian Soc. Periodontol. $2010,14,72-79$. [CrossRef]

53. Kong, J.; Yu, S. Fourier transform infrared spectroscopic analysis of protein secondary structures. Acta Biochim. Biophys. Sin. (Shanghai) 2007, 39, 549-559. [CrossRef] [PubMed]

54. Rey, C.; Collins, B.; Goehl, T.; Dickson, I.R.; Glimcher, M.J. The carbonate environment in bone-mineral a resolution-enhanced Fourier-Transform Infrared-Spectroscopy study. Calcif. Tissue Int. 1989, 45, 157-164. [CrossRef] [PubMed]

55. Lussi, A.; Carvalho, T.S. Analyses of the Erosive Effect of Dietary Substances and Medications on Deciduous Teeth. PLoS ONE 2015, 10, e0143957. [CrossRef] [PubMed]

56. Beniash, E.; Stifler, C.A.; Sun, C.Y.; Jung, G.S.; Qin, Z.; Buehler, M.J.; Gilbert, P. The hidden structure of human enamel. Nat. Commun. 2019, 10, 4383. [CrossRef]

57. Reyes-Gasga, J.; Martínez-Piñeiro, E.L.; Rodríguez-Álvarez, G.; Tiznado-Orozco, G.E.; García-García, R.; Brès, E.F. XRD and FTIR crystallinity indices in sound human tooth enamel and synthetic hydroxyapatite. Mater Sci Eng C Mater Biol Appl. 2013, 33, 4568-4574. [CrossRef] 